\title{
Article \\ The Differential Impact of COVID-19 Lockdown on Sleep Quality, Insomnia, Depression, Stress, and Anxiety among Late Adolescents and Elderly in Italy
}

\author{
Giulia Amicucci ${ }^{1,2,+}\left(\mathbb{D}\right.$, Federico Salfi $\left.{ }^{1,+}{ }^{(}\right)$, Aurora $D^{\prime}$ Atri $^{1}{ }^{1}$, , Lorenzo Viselli ${ }^{1}$ and Michele Ferrara ${ }^{1, *} \mathbb{D}$ \\ 1 Department of Biotechnological and Applied Clinical Sciences, University of L'Aquila, 67100 L'Aquila, Italy; \\ giulia.amicucci@uniroma1.it (G.A.); federico.salfi@graduate.univaq.it (F.S.); aurora.datri@univaq.it (A.D.); \\ lorenzo.viselli@graduate.univaq.it (L.V.) \\ 2 Department of Psychology, "Sapienza" University of Rome, 00185 Rome, Italy \\ * Correspondence: michele.ferrara@univaq.it \\ + These authors share the first authorship.
}

check for

updates

Citation: Amicucci, G.; Salfi, F.;

D'Atri, A.; Viselli, L.; Ferrara, M. The

Differential Impact of COVID-19

Lockdown on Sleep Quality,

Insomnia, Depression, Stress, and Anxiety among Late Adolescents and Elderly in Italy. Brain Sci. 2021, 11, 1336. https://doi.org/10.3390/ brainsci11101336

Academic Editor: Célyne Bastien

Received: 2 September 2021

Accepted: 7 October 2021

Published: 11 October 2021

Publisher's Note: MDPI stays neutral with regard to jurisdictional claims in published maps and institutional affiliations.

Copyright: (c) 2021 by the authors. Licensee MDPI, Basel, Switzerland. This article is an open access article distributed under the terms and conditions of the Creative Commons Attribution (CC BY) license (https:// creativecommons.org/licenses/by/ $4.0 /)$.

\begin{abstract}
The restraining measures due to the COVID-19 outbreak deeply affected the general population's sleep health and psychological status. The current literature proposes young and older people as two particularly at-risk groups. However, the differential impact of the lockdown period in these specific age categories needs to be disentangled. Through a web-based survey adopting validated questionnaires, we evaluated and compared sleep quality/habits, insomnia, perceived stress, depression, and anxiety symptoms of Italian late adolescents $(n=670$; mean age \pm SD, $19.38 \pm 0.74,18-20$ years $)$ and elderly $(n=253 ; 68.18 \pm 2.79,65-75$ years $)$. Young respondents reported more severe insomnia symptoms, worse subjective sleep quality, longer sleep latency, higher daytime dysfunction, and a more prevalent disruption of sleep habits (bedtime, get-up time, nap) than the elderly. On the other hand, older participants showed shorter sleep duration, lower habitual sleep efficiency, and greater use of sleep medications. Finally, the younger population displayed higher levels of depression and perceived stress. Our findings indicate that the lockdown period had more pervasive repercussions on sleep and the mental health of late adolescents. The implementation of supportive strategies is encouraged for this vulnerable population group.
\end{abstract}

Keywords: lockdown; COVID-19 pandemic; late adolescents; elderly; sleep; mental health; stress

\section{Introduction}

The spread of SARS-CoV-2 in China during December 2019 quickly led to the development of a pandemic [1]. Italy was the first European country to impose a total lockdown (9 March-4 May 2020), adopting unprecedented restrictive measures to reduce the infection and death rates. Social isolation, quarantine, mandatory closure of schools, and most work activities deeply compromised the overall mental health and psychological well-being of Italian citizens $[2,3]$. The pandemic emergency was marked by increased stress and an exacerbation of anxiety and depressive symptoms among the general population. Moreover, the COVID-19 outbreak pervasively altered sleep patterns, as evidenced by poorer sleep quality and increased insomnia levels [3-5].

During the lockdown, the elderly could be considered as one of the most at-risk population groups. As far as sleep is concerned, older people normally exhibit several alterations of sleep patterns due to the physiological aging process [6]. Moreover, the elderly's sleep problems can be exacerbated by an increasing prevalence of multimorbidity, polypharmacy, and psychosocial factors [7]. Several studies showed that older adults report poor sleep quality [8], with insomnia as the most common sleep disorder [9,10]. Notably, the prevalence of sleep disturbances is higher in the elderly than in the young population $[8,10]$. 
The pandemic-related factors, including home confinement, social isolation, and the fear of contracting the virus, could directly impact the sleep of older adults [11]. However, the relationship between sleep and COVID-19 outbreak in the elderly is still unclear. Recent studies indicated that older age represented a protective factor for sleep health $[3,12]$. During home confinement, the younger population reported lower sleep quality [13], increased occurrence of sleep problems [14,15], and worsening of existing sleep problems [14] compared to older people. Conversely, other investigations identified advanced age as a risk factor for sleep disturbances [16], being associated with a decline of sleep quality [17], especially in older individuals with depressive and anxiety symptoms [18]. A recent study also showed that older age represented a significant predictor of a higher association between sleep problems and psychological distress [19]. Moreover, social isolation could exacerbate feelings of loneliness which, in turn, could compromise sleep and psychological health among the older population $[20,21]$.

The fear of contagion could be considered a further factor that can negatively affect general well-being due to the high morbidity and mortality rates in the elderly [22]. However, several studies showed that the older population reported less psychological distress during the COVID-19 outbreak (for a review, [23]), exhibiting higher levels of resilience than the younger counterpart [24]. Although these results may be counterintuitive, it has been shown that late adolescents are more prone to suffer the repercussions of the lockdown on their mental health, representing the less resilient population group than previous generations [25]. Young people exhibited even lower resilience during the pandemic when compared with normative data [26]. Consistently, they seemed to represent an age group strongly affected by the current emergency. Several studies indicated that the younger population showed higher levels of stress, anxiety, and depression [2,27], also ascribable to the deeply disrupted education and social life [28].

In the present study, through a web-based survey, we investigated sleep quality/habits, insomnia, depression, perceived stress, and anxiety symptoms of two particularly at-risk age population groups, that is, late adolescents (18-20 years) and elderly (65-75 years) during the lockdown of Spring 2020 in Italy. We hypothesized to highlight differences in sleep quality/habits, insomnia, and mental health between late adolescents and elderly. However, the above-reported articulated literature does not allow hypothesizing the direction and the extent of the effects of the lockdown on these specific age groups. Therefore, we exploratively compared these two Italian samples to identify specific age-related vulnerabilities for sleep disturbances and psychological problems during the home confinement due to the COVID-19 outbreak. Determining the most vulnerable population categories is essential for designing and implementing specific interventions to mitigate the potential repercussions on sleep and mental health.

\section{Materials and Methods}

\subsection{Participants}

The present study belongs to a larger research project aimed at identifying and understanding the sleep-related and psychological consequences of the COVID-19 pandemic on the Italian population [4].

A total of 13,989 Italian citizens took part in a web-based survey during the lockdown period due to the first contagion wave of COVID-19 (25 March-3 May 2020).

According to the present study's objective, two subsamples of participants were selected from the whole sample. The first subsample comprised 253 elderly subjects aged 65 to 75 years (mean age \pm SD, $68.18 \pm 2.79,104$ males), while the other subsample consisted of 670 late adolescents (18-20 years, $19.38 \pm 0.74,182$ males).

\subsection{Procedure}

The survey was disseminated through a snowball technique, using social networks (Facebook, WhatsApp, Instagram, and Twitter). Firstly, information about age, gender, the perceived impact of the lockdown on sleep quality, the occurred changes in bedtime, 
get-up time, and nap habits were collected. Secondly, the survey comprised an evaluation of sleep quality, the severity of insomnia symptoms, and chronotype, using a set of validated questionnaires.

The Pittsburgh Sleep Quality Index (PSQI) [29] was used to assess sleep quality. It is a 19-item questionnaire that includes the evaluation of seven different sleep dimensions: sleep quality, sleep duration, sleep latency, habitual sleep efficiency, sleep disorders, the use of sleep medications, and daytime dysfunction. A higher total score (range 0-21) indicates more severe sleep problems. A cut-off score of 5 is a valid indicator of poor sleep quality [30].

Insomnia symptoms were evaluated using the Insomnia Severity Index (ISI) [31], a 7-item clinical instrument to assess the severity of insomnia condition (range 0-28). A score ranging between 0 and 7 denotes no significant insomnia, between 8 and 14 subthreshold insomnia, from 15 to 21 moderate insomnia, and a total score of 22-28 identify severe insomnia condition [32].

The Morningness-Eveningness Questionnaire-reduced version (MEQr) [33] is a validated 5-item questionnaire (range 4-25) used to identify circadian typologies (4-10: eveningtype; 11-18: neither-type; 19-25: morning-type).

Finally, we collected information about depression, perceived stress, and anxiety symptoms, using the Beck Depression Inventory-second edition (BDI-II) [34], the Perceived Stress Scale-10 (PSS-10) [35], and the state-anxiety subscale of the State-Trait Anxiety Inventory (STAI-X1) [36], respectively.

The BDI-II is a 21-item questionnaire widely used in clinical practice to evaluate depressive symptoms (range 0-63). Validated cut-off scores are used to identify the severity of depression conditions (0-13: no or minimal depression, 14-19: mild depression, 20-28: moderate depression, and 29-63: severe depression).

The PSS-10 is a 10-item questionnaire used to evaluate thoughts and feelings referred to stressful events. A higher total score (range 0-40) identifies more significant perceived stress.

The STAI-X1 is a 20-item scale included in the Cognitive Behavioral Assessment battery 2.0 [37]. A higher total score (range 20-80) denotes greater state anxiety.

In order to guarantee greater reliability of the collected responses, the compilation of the last three questionnaires (BDI-II, PSS-10, STAI-X1) was made optional. Of the older respondents, $67.6 \%$ and $64.0 \%$ completed the BDI-II and the 10-PSS, respectively, while $63.6 \%$ completed all the questionnaires. On the other hand, among young respondents, $69.6 \%$ and $63.0 \%$ compiled BDI-II and PSS-10, respectively, and $61.0 \%$ of them also completed the STAI-X1.

\subsection{Statistical Analysis}

The statistical analyses were performed using SPSS v.22 (IBM Corp., Armonk, NY, USA).

The questionnaire scores (PSQI, ISI, MEQr, BDI-II, PSS-10, STAI-X1) of the two subsamples (Elderly, Young) were compared using the Kruskal-Wallis test due to violation of the normality/heteroscedasticity assumptions. The same analysis was applied to bedtime, get-up time, and each sub-component of the PSQI to further understand putative differences in sleep quality/habits between the two groups (Elderly, Young).

We excluded 16 older and 62 young respondents from the analysis on PSQI total score and one of its sub-components (habitual sleep efficiency) due to compilation errors, as respondents reported longer sleep duration than time in bed.

Moreover, we carried out frequency analyses to investigate the proportion within the two groups (Elderly, Young) of the reported impact of the lockdown period on sleep (negative, none, positive) and the changes of bedtime (advanced, unchanged, delayed), get-up time (advanced, unchanged, delayed), and nap habits (increased, unchanged, reduced). Likewise, the same analysis was applied to the PSQI and ISI scores identifying the proportion of poor sleepers and clinical insomniacs through the validated cut-offs. Then, we performed Chi-square tests to evaluate the association between the group membership (Elderly, Young) and the above-mentioned self-report variables. 
All the analyses were two-tailed, and the level of significance was set at $p<0.05$. All $p$ values were corrected for multiple comparisons with false discovery rate (FDR) [38]. Eta squared $\left(\varepsilon^{2}\right)$ and Cramer's $V$ were computed to provide effect size estimates for KruskalWallis and Chi-square tests, respectively.

\section{Results}

\subsection{Sleep Variables}

The two groups did not significantly differ in overall sleep quality (Figure 1), as showed by the analysis on PSQI total scores (mean \pm SD; Elderly: $7.13 \pm 3.95$; Young: $6.79 \pm 3.33 ; \chi^{2}=0.68, p=0.41, \varepsilon^{2}<0.001$ ). However, the comparisons on PSQI subcomponents highlighted several significant differences (Table 1). The elderly showed shorter sleep duration, lower habitual sleep efficiency, and greater use of sleep medications than young participants. On the other hand, they reported better subjective sleep quality, shorter sleep latency, and lower daytime dysfunction than late adolescents. Moreover, older respondents reported an earlier bedtime and get-up time.
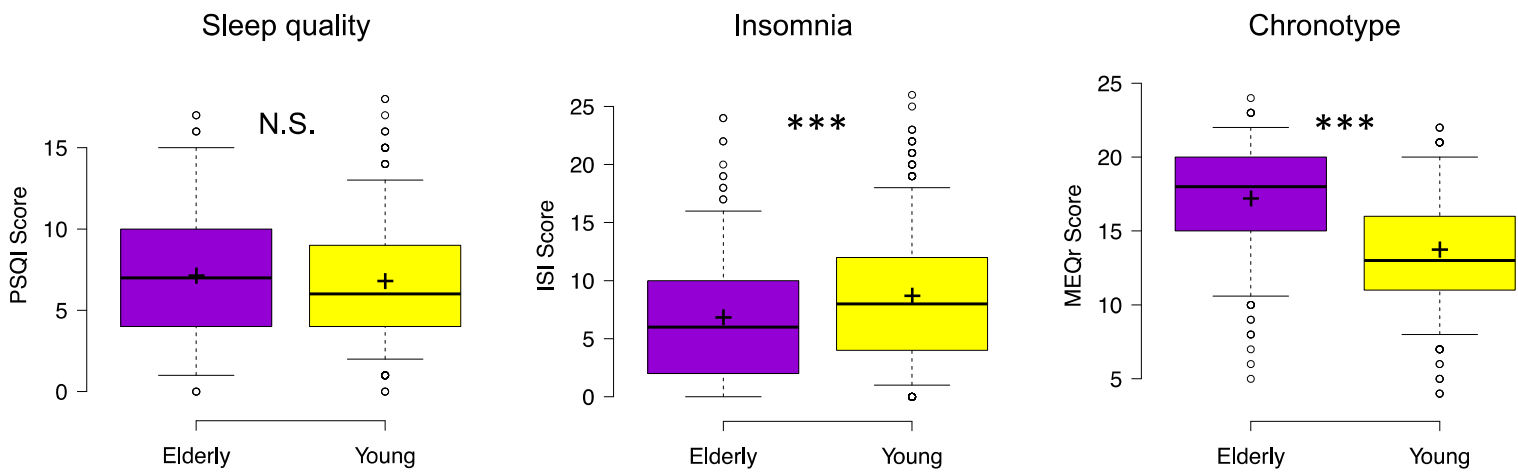

Figure 1. Sleep quality (PSQI), severity of insomnia symptoms (ISI), and inclination to Morningness-Eveningness (MEQr) for elderly and young respondents during the COVID-19 lockdown. Center lines show the medians; box limits indicate the 25th and 75th percentiles; whiskers extend to 5th and 95th percentiles, dots represent outliers; crosses represent sample means. Significant differences of Kruskal-Wallis test between elderly (violet) and young (yellow) participants are indicated with asterisks $(* * *<0.001)$. Abbreviations: PSQI, Pittsburgh Sleep Quality Index; ISI, Insomnia Severity Index; MEQr, Morningness-Eveningness Questionnaire-reduced version; N.S., not significant.

Table 1. Mean and standard deviation (SD) of the two groups (Elderly, Young), and the corresponding statistical comparisons (Kruskal-Wallis: $\chi^{2}, p, \varepsilon^{2}$ ), for bedtime, get-up time, and the PSQI sub-components.

\begin{tabular}{|c|c|c|c|c|c|}
\hline & $\begin{array}{c}\text { Elderly } \\
\text { (65-75 Age) }\end{array}$ & $\begin{array}{c}\text { Young } \\
\text { (18-20 Age) }\end{array}$ & \multirow[t]{2}{*}{$\chi^{2}$} & \multirow[t]{2}{*}{$p$} & \multirow[t]{2}{*}{$\varepsilon^{2}$} \\
\hline & \multicolumn{2}{|c|}{ Mean \pm SD } & & & \\
\hline Bedtime (hh:mm) & $23: 46 \pm 1: 12$ & $1: 12 \pm 1: 41$ & 138.25 & $<0.001$ & 0.15 \\
\hline Get-up time (hh:mm) & $07: 55 \pm 1: 26$ & $9: 36 \pm 1: 41$ & 208.23 & $<0.001$ & 0.23 \\
\hline \multicolumn{6}{|c|}{ PSQI sub-components } \\
\hline Subjective sleep quality & $1.16 \pm 0.77$ & $1.39 \pm 0.79$ & 15.75 & $<0.001$ & 0.02 \\
\hline Sleep latency & $1.11 \pm 1.01$ & $1.57 \pm 1.00$ & 36.76 & $<0.001$ & 0.04 \\
\hline Sleep duration & $1.08 \pm 0.92$ & $0.50 \pm 0.75$ & 93.32 & $<0.001$ & 0.10 \\
\hline Habitual sleep efficiency & $1.11 \pm 1.14$ & $0.55 \pm 0.89$ & 49.26 & $<0.001$ & 0.06 \\
\hline Sleep disturbances & $1.40 \pm 0.65$ & $1.34 \pm 0.58$ & 1.37 & 0.28 & 0.001 \\
\hline Sleep medications & $0.51 \pm 1.05$ & $0.23 \pm 0.69$ & 14.55 & $<0.001$ & 0.02 \\
\hline Daytime dysfunction & $0.58 \pm 0.65$ & $1.15 \pm 0.81$ & 93.86 & $<0.001$ & 0.10 \\
\hline
\end{tabular}

The analysis of ISI scores highlighted a significant difference between the two groups $\left(\chi^{2}=24.43, p<0.001, \varepsilon^{2}=0.03\right)$. Elderly participants showed lower insomnia symptoms $(6.84 \pm 5.34)$ than young respondents $(8.69 \pm 5.33)$. 
Furthermore, the analysis on MEQr scores displayed a significant difference between the two groups $\left(\chi^{2}=150.37, p<0.001, \varepsilon^{2}=0.16\right)$. Elderly respondents showed a greater inclination to morning chronotype $(17.19 \pm 3.61)$ than young subjects $(13.74 \pm 3.47)$.

Finally, we observed significant associations between the two groups and the perceived impact of the restraining measures, the reported changes in bedtime, get-up time, and nap habits, and the prevalence of clinical insomnia conditions (Table 2). Prevalence data showed that more than six out of ten late adolescents reported a negative impact of the lockdown period, while a lower rate of older respondents reported a negative impact of the restraining measures.

Table 2. Prevalence of the lockdown-related perceived impact on sleep, the reported changes of bedtime, get-up time, and nap habits, and the proportion of poor/good sleepers and clinical insomnia conditions within the two groups (Elderly, Young). Chi-square test results are also reported ( $\chi^{2}, p$, Cramer's V).

\begin{tabular}{|c|c|c|c|c|c|c|}
\hline & & $\begin{array}{c}\text { Elderly } \\
\text { (65-75 Age) }\end{array}$ & $\begin{array}{c}\text { Young } \\
\text { (18-20 Age) }\end{array}$ & \multirow[t]{2}{*}{$\chi^{2}$} & \multirow[t]{2}{*}{$p$} & \multirow[t]{2}{*}{ Cramer's V } \\
\hline & & \multicolumn{2}{|c|}{$n(\%)$} & & & \\
\hline \multirow{3}{*}{$\begin{array}{l}\text { Perceived } \\
\text { impact }\end{array}$} & Negative & 109 (43.1) & $431(64.3)$ & \multirow{3}{*}{64.42} & \multirow{3}{*}{$<0.001$} & \multirow{3}{*}{0.26} \\
\hline & None & $110(43.5)$ & $120(17.9)$ & & & \\
\hline & Positive & $34(13.4)$ & 119 (17.8) & & & \\
\hline \multirow{3}{*}{ Bedtime } & Advanced & $19(7.5)$ & $36(5.4)$ & \multirow{3}{*}{123.48} & \multirow{3}{*}{$<0.001$} & \multirow{3}{*}{0.37} \\
\hline & Unchanged & $142(56.1)$ & $134(20.0)$ & & & \\
\hline & Delayed & $92(36.4)$ & $500(74.6)$ & & & \\
\hline \multirow{3}{*}{ Get-up time } & Advanced & $27(10.7)$ & $57(8.5)$ & \multirow{3}{*}{106.66} & \multirow{3}{*}{$<0.001$} & \multirow{3}{*}{0.34} \\
\hline & Unchanged & 125 (49.4) & $116(17.3)$ & & & \\
\hline & Delayed & $101(39.9)$ & $497(74.2)$ & & & \\
\hline \multirow{3}{*}{ Nap habit } & Increased & $33(13.0)$ & $124(18.5)$ & \multirow{3}{*}{50.19} & \multirow{3}{*}{$<0.001$} & \multirow{3}{*}{0.23} \\
\hline & Unchanged & $196(77.5)$ & $355(53.0)$ & & & \\
\hline & Reduced & $24(9.5)$ & $191(28.5)$ & & & \\
\hline \multirow{2}{*}{ Sleep quality } & Poor & $151(63.7)$ & $365(60.0)$ & \multirow{2}{*}{0.97} & \multirow{2}{*}{0.32} & \multirow{2}{*}{0.03} \\
\hline & Good & $86(36.3)$ & $243(40.0)$ & & & \\
\hline \multirow{4}{*}{ Insomnia } & Severe & $4(1.6)$ & $10(1.5)$ & \multirow{4}{*}{13.35} & \multirow{4}{*}{0.004} & \multirow{4}{*}{0.12} \\
\hline & Moderate & $22(8.7)$ & $96(14.3)$ & & & \\
\hline & Subthreshold & 74 (29.2) & 245 (36.6) & & & \\
\hline & No & $153(60.5)$ & 319 (47.6) & & & \\
\hline
\end{tabular}

Moreover, a higher proportion of elderly participants showed unchanged sleep patterns (bedtime, get-up time, and nap habits) than young subjects. Remarkably, three out of four young respondents declared a delayed sleep phase. Finally, older people were characterized by a lower rate of clinical insomnia conditions compared to young people. Chi-square tests did not show a significant association between the two groups and the prevalence of poor and good sleepers.

In the light of the higher proportion of women in the young sample and the welldocumented gender differences of sleep problems during the lockdown period [39], we performed control analyses that excluded a possible gender bias in our pattern of results (data not shown).

\subsection{Psychological Variables}

There was a significant difference between the two groups in severity of depression symptoms $\left(\chi^{2}=54.13, p<0.001, \varepsilon^{2}=0.08\right)$, and perceived stress $\left(\chi^{2}=72.99, p<0.001\right.$, $\left.\varepsilon^{2}=0.12\right)$, while anxiety measure did not differ between elderly and young respondents $\left(\chi^{2}=1.03, p=0.33, \varepsilon^{2}=0.002\right)$. As showed in Figure 2, notwithstanding that the two groups 
did not differ in STAI-X1 scores (mean \pm SD; Elderly: $48.20 \pm 9.74$; Young: $49.0 \pm 9.59$ ), older participants showed less severe depression symptoms (BDI-II: $9.01 \pm 8.21$ ) and lower stress levels (PSS-10: $13.88 \pm 7.10$ ) than late adolescents (BDI-II: $14.45 \pm 9.90$; PSS-10: $19.95 \pm 7.31$ ). Control analyses including gender factor in the models confirmed the differences between the two groups on depression and perceived stress.

Depression

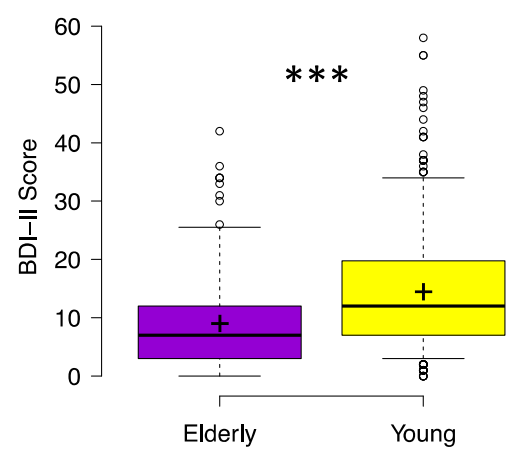

Perceived stress

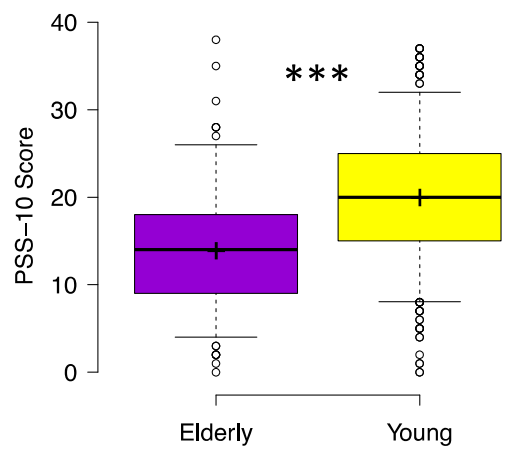

Anxiety

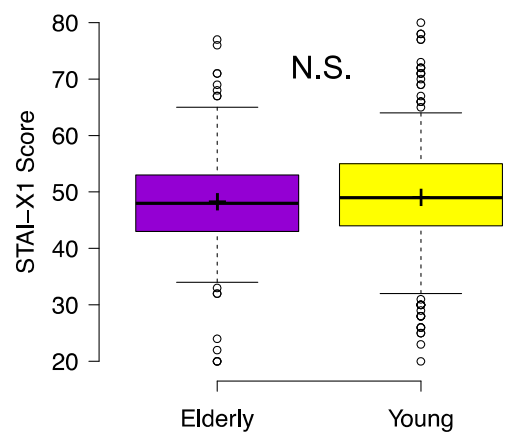

Figure 2. Depression symptoms (BDI-II), perceived stress (PSS-10), and anxiety (STAI-X1) for elderly and young respondents during the COVID-19 lockdown. Center lines show the medians; box limits indicate the 25th and 75th percentiles; whiskers extend to 5th and 95th percentiles, dots represent outliers; crosses represent sample means. Significant differences of Kruskal-Wallis test between elderly (violet) and young (yellow) participants are indicated with asterisks $\left({ }^{* * *} p<0.001\right)$. Abbreviations: BDI-II, Beck Depression Inventory-second edition, PSS-10, Perceived Stress Scale-10; STAI-X1, state-anxiety subscale of the State-Trait Anxiety Inventory; N.S., not significant.

\section{Discussion}

According to the study's hypothesis, we highlighted several differences in sleep and psychological health between late adolescents and older people during the lockdown of Spring 2020 in Italy.

Two-thirds of young participants $(64.3 \%)$ perceived a negative impact of the restraining measures on their sleep, a greater prevalence than older adults (43.1\%). Furthermore, three out of four young respondents showed a delayed sleep phase (bedtime, get-up time). On the other hand, elderly subjects prevalently showed unchanged sleep patterns.

Maintaining the sleep schedule has been suggested as a protective factor to deal with sleep problems during home confinement [40]. In line with this assumption, older people presented lower severity of insomnia than young participants. Conversely, more than half of the late adolescents reported insomnia symptoms from subthreshold to severe extent.

Paradoxically, although the differences in insomnia levels between the two groups, we did not identify significant differences in overall sleep quality. This evidence could be ascribable to the different sleep dimensions covered by the PSQI, whose sum gives rise to the sleep quality measure. Older participants showed shorter sleep duration, lower habitual sleep efficiency, and greater use of sleep medications, in line with the well-documented sleep changes occurring across the lifespan $[8,10,41]$. We hypothesize that these variables could hardly be affected by the home confinement period in the short term, balancing the outcomes of the other PSQI sub-components. On the other hand, late adolescents showed a worse subjective sleep quality, longer sleep latency, and higher daytime dysfunction, putatively reflecting the more severe insomnia symptoms of this population.

Moreover, a high percentage of late adolescents declared a reduction of naps. Young people's well-known biological tendency to late sleep timing is typically misaligned with the social clock (academic pressure and social activities) [42,43], configuring the so-called social jetlag phenomenon [44]. This situation results in an overall reduction of sleep duration and an accumulated sleep debt during the weekdays among adolescents, leading them to develop compensatory nap habits [45]. As the lockdown period represented an unprecedented condition that unlocked time for sleep for most of the population, we hypothesize 
that the greater reduction of nap habits of late adolescents reflected the reduction of the social jetlag phenomenon documented among the young population during the period of restraining measures due to COVID-19 outbreak [46].

Although the elderly population exhibits the highest risk of morbidity and mortality during the current pandemic [22], late adolescents seemed to suffer more from the restrictive measures on the psychological side. In line with the current literature on mental health during the pandemic [23], older respondents reported less severe depression symptoms and lower stress levels. However, we did not observe a significant difference in anxiety between the two groups.

Our results are supported by previous research [47], which showed that older people exhibit a higher level of resilience in difficult times than young people, as they experienced greater stressful events during their lifetime, developing better emotional regulation and coping strategies $[48,49]$. Consistent with this interpretation, a recent study on the Italian population showed that resilience mediated the relationship between pandemic-related stressful events and depression, anxiety, and perceived stress, while age moderated the mediating effect of resilience [24]. Moreover, in line with our findings, another study highlighted that young people presented higher levels of depression, perceived stress, and insomnia than the older counterpart [2].

Furthermore, according to the pre-COVID literature [50], the elderly population reported earlier bedtime and get-up time, and a tendency to morning chronotype. This evidence could constitute a protective factor of older people, as morningness was associated with higher resilience [51-53], lower perceived stress [54], and a lower tendency to develop post-traumatic stress disorder (PTSD) $[55,56]$. In this regard, we recently proposed the evening chronotype as a vulnerability factor during the lockdown period $[4,57]$.

Moreover, the current pandemic emergency impacted younger's education, contributing to impair mental health of university students [58,59].

Late adolescents were particularly affected by isolation resulting from social distancing [28,60], considering the prominent role of peers and social connections at this stage of life. We hypothesize that these factors could play a role in explaining the greater psychological distress of the young population during the COVID-19 lockdown.

Finally, limited social interactions led to a pervasive increase in the use of digital devices in the hours before falling asleep [61], a deeply rooted habit in our society already before the isolation period among young people. Increased screen exposure has been associated with reduced sleep quality, exacerbation of insomnia symptoms, reduced sleep duration, and longer sleep onset latency during home confinement [61]. Sleep problems could, in turn, negatively affect the psychological well-being of the young population [62]. Of note, excessive screen time was associated with a concomitant higher rate of anxiety and depression symptoms during the lockdown period, especially among young people [63].

To our knowledge, this is the first study on the Italian population aimed at comparing sleep problems and psychological well-being between late adolescents and the older population. However, we must report some limitations. The first one consists of the nonprobabilistic sampling technique adopted, as the recruitment of the sample was performed via social networks. This recruitment strategy could limit the generalization of our results to the older population. Moreover, our samples comprised a higher prevalence of women, in particular in the young group. Nevertheless, control analyses confuted a putative gender bias due to the unbalanced gender composition of the two samples. Finally, under-eighteen years old people were not recruited. Future investigations are necessary to clarify the impact of the COVID-19 pandemic on sleep and psychological well-being in this younger population group, considering the strong relationship between sleep and mental health and their influence in the transition toward adulthood [64].

In conclusion, considering the well-known bidirectional relationship between sleep problems and psychological well-being [65], interventions to improve sleep health should be implemented among the young population. Paying attention to sleep hygiene, keeping a stable sleep schedule, and avoiding the overuse of electronic devices before bedtime 
may prove to be effective strategies to preserve both sleep and psychological health [66]. It is also necessary to implement psychological interventions that, in turn, can support sleep health.

The pandemic continues to plague the daily routine of the general population worldwide. Further research is recommended to evaluate the differential long-term repercussions among late adolescents and the elderly population. This unprecedented period is having a persistent negative impact on the sleep and mental health of the Italian population, as evidenced by the increased perceived stress, and the unchanged prevalence of poor sleepers and moderate/severe depression conditions during the second contagion wave of Winter 2020 compared with the first one [57]. Therefore, we suggest the development of prompt supportive strategies focused on young people, who appeared to be the most vulnerable population group. On the other hand, it is also recommended monitoring older adults sleep health and psychological status, as they may develop a concomitant vulnerability over time [24].

Author Contributions: Conceptualization, G.A. and F.S.; methodology, F.S.; formal analysis, G.A. and F.S.; investigation, G.A., F.S. and L.V.; data curation, G.A. and F.S.; writing-original draft preparation, G.A. and F.S.; writing—review and editing, G.A., F.S., A.D., L.V. and M.F.; supervision, M.F.; project administration, M.F. All authors have read and agreed to the published version of the manuscript.

Funding: This research received no external funding.

Institutional Review Board Statement: The study was conducted according to the guidelines of the Declaration of Helsinki and approved by the Institutional Review Board of the University of L'Aquila (protocol code 43006, approved 12 June 2020).

Informed Consent Statement: Informed consent was obtained from all subjects involved in the study.

Data Availability Statement: The data presented in this study are available on request from the corresponding author.

Conflicts of Interest: The authors declare no conflict of interest.

\section{References}

1. World Health Organization. Coronavirus Disease (COVID-2019) Situation Reports; WTO: Geneva, Switzerland, 2020.

2. Rossi, R.; Socci, V.; Talevi, D.; Mensi, S.; Niolu, C.; Pacitti, F.; Di Marco, A.; Rossi, A.; Siracusano, A.; Di Lorenzo, G. COVID-19 Pandemic and Lockdown Measures Impact on Mental Health Among the General Population in Italy. Front. Psychiatry 2020, 11, 790. [CrossRef]

3. Gualano, M.R.; Lo Moro, G.; Voglino, G.; Bert, F.; Siliquini, R. Effects of Covid-19 Lockdown on Mental Health and Sleep Disturbances in Italy. Int. J. Environ. Res. Public Health 2020, 17, 4779. [CrossRef]

4. Salfi, F.; Lauriola, M.; D’Atri, A.; Amicucci, G.; Viselli, L.; Tempesta, D.; Ferrara, M. Demographic, psychological, chronobiological, and work-related predictors of sleep disturbances during the COVID-19 lockdown in Italy. Sci. Rep. 2021, 11, 11416. [CrossRef] [PubMed]

5. Alfonsi, V.; Gorgoni, M.; Scarpelli, S.; Zivi, P.; Sdoia, S.; Mari, E.; Fraschetti, A.; Ferlazzo, F.; Giannini, A.M.; De Gennaro, L. COVID-19 lockdown and poor sleep quality: Not the whole story. J. Sleep Res. 2021, 30, e13368. [CrossRef] [PubMed]

6. Gulia, K.K.; Kumar, V.M. Sleep disorders in the elderly: A growing challenge. Psychogeriatrics 2018, 18, 155-165. [CrossRef] [PubMed]

7. Miner, B.; Haven, N.; Kryger, M.H.; Avenue, C.; Haven, W. Sleep in the Aging Population. HHS Public Access. 2018, 12, 31-38. [CrossRef]

8. Li, J.; Vitiello, M.V.; Gooneratne, N.S. Sleep in Normal Aging. Sleep Med. Clin. 2018, 13, 1-11. [CrossRef]

9. Kamel, N.S.; Gammack, J.K. Insomnia in the Elderly: Cause, Approach, and Treatment. Am. J. Med. 2006, 119, 463-469. [CrossRef]

10. Patel, D.; Steinberg, J.; Patel, P. Insomnia in the Elderly: A Review. J. Clin. Sleep Med. 2018, 14, 1017-1024. [CrossRef]

11. Pires, G.N.; Ishikura, I.A.; Xavier, S.D.; Petrella, C.; Piovezan, R.D.; Xerfan, E.M.S.; Andersen, M.L.; Tufik, S. Sleep in Older Adults and Its Possible Relations With COVID-19. Front. Aging Neurosci. 2021, 13, 647875. [CrossRef]

12. Pinto, J.; van Zeller, M.; Amorim, P.; Pimentel, A.; Dantas, P.; Eusébio, E.; Neves, A.; Pipa, J.; Clara, E.S.; Santiago, T.; et al. Sleep quality in times of Covid-19 pandemic. Sleep Med. 2020, 74, 81-85. [CrossRef]

13. Yuan, S.; Liao, Z.; Huang, H.; Jiang, B.; Zhang, X.; Wang, Y.; Zhao, M. Comparison of the Indicators of Psychological Stress in the Population of Hubei Province and Non-Endemic Provinces in China During Two Weeks During the Coronavirus Disease 2019 (COVID-19) Outbreak in February 2020. Med. Sci. Monit. 2020, 26, 1-10. [CrossRef] 
14. Barros, M.B.D.A.; Lima, M.G.; Malta, D.C.; Szwarcwald, C.L.; Azevedo, R.C.S.D.; Romero, D.; Souza Júnior, P.R.B.D.; Azevedo, L.O.; Machado, Í.E.; Damacena, G.N.; et al. Relato de Tristeza/Depressão, Nervosismo/Ansiedade e Problemas de Sono Na População Adulta Brasileira Durante a Pandemia de COVID-19. Epidemiologia e Serviços de Saúde 2020, 29, e2020427. [CrossRef] [PubMed]

15. Beck, F.; Léger, D.; Fressard, L.; Peretti-Watel, P.; Verger, P.; The Coconel Group. COVID-19 health crisis and lockdown associated with high level of sleep complaints and hypnotic uptake at the population level. J. Sleep Res. 2021, 30, e13119. [CrossRef] [PubMed]

16. Wang, J.; Gong, Y.; Chen, Z.; Wu, J.; Feng, J.; Yan, S.; Lv, C.; Lu, Z.; Mu, K.; Yin, X. Sleep disturbances among Chinese residents during the Coronavirus Disease 2019 outbreak and associated factors. Sleep Med. 2020, 74, 199-203. [CrossRef] [PubMed]

17. De Pue, S.; Gillebert, C.; Dierckx, E.; Vanderhasselt, M.-A.; De Raedt, R.; Bussche, E.V.D. The impact of the COVID-19 pandemic on wellbeing and cognitive functioning of older adults. Sci. Rep. 2021, 11, 4636. [CrossRef]

18. Cigiloglu, A.; Ozturk, Z.A.; Efendioglu, E.M. How have older adults reacted to coronavirus disease 2019? Psychogeriatrics 2021, 21, 112-117. [CrossRef]

19. Alimoradi, Z.; Broström, A.; Tsang, H.W.; Griffiths, M.D.; Haghayegh, S.; Ohayon, M.M.; Lin, C.-Y.; Pakpour, A.H. Sleep problems during COVID-19 pandemic and its' association to psychological distress: A systematic review and meta-analysis. EClinicalMedicine 2021, 36, 100916. [CrossRef]

20. Grossman, E.S.; Hoffman, Y.S.G.; Palgi, Y.; Shrira, A. COVID-19 related loneliness and sleep problems in older adults: Worries and resilience as potential moderators. Pers. Individ. Differ. 2021, 168, 110371. [CrossRef]

21. Rout, N. Risks to the elderly during the coronavirus (COVID-19) pandemic 2019-2020. J. Geriatr. Care Res. 2020, 7, 27-28.

22. Onder, G.; Rezza, G.; Brusaferro, S. Case-Fatality Rate and Characteristics of Patients Dying in Relation to COVID-19 in Italy. JAMA 2020, 323, 1775-1776. [CrossRef]

23. Lebrasseur, A.; Fortin-Bédard, N.; Lettre, J.; Raymond, E.; Bussières, E.-L.; Lapierre, N.; Faieta, J.; Vincent, C.; Duchesne, L.; Ouellet, M.-C.; et al. Impact of the COVID-19 Pandemic on Older Adults: Rapid Review. JMIR Aging 2021, 4, e26474. [CrossRef]

24. Rossi, R.; Jannini, T.B.; Socci, V.; Pacitti, F.; Di Lorenzo, G. Stressful Life Events and Resilience During the COVID-19 Lockdown Measures in Italy: Association With Mental Health Outcomes and Age. Front. Psychiatry 2021, 12, 635832. [CrossRef]

25. Carson, J.; Prescott, J.; Allen, R.; McHugh, S. Winter is coming: Age and early psychological concomitants of the Covid-19 pandemic in England. J. Public Ment. Health 2020, 19, 221-230. [CrossRef]

26. Killgore, W.D.S. Psychological resilience during the COVID-19 lockdown. Psychiatry Res. 2020, 291, 113216. [CrossRef]

27. Ueda, M.; Stickley, A.; Sueki, H.; Matsubayashi, T. Mental health status of the general population in Japan during the COVID-19 pandemic. Psychiatry Clin. Neurosci. 2020, 74, 505-506. [CrossRef] [PubMed]

28. Nwachukwu, I.; Nkire, N.; Shalaby, R.; Hrabok, M.; Vuong, W.; Gusnowski, A.; Surood, S.; Urichuk, L.; Greenshaw, A.J.; Agyapong, V.I.O. COVID-19 Pandemic: Age-Related Differences in Measures of Stress, Anxiety and Depression in Canada. Int. J. Environ. Res. Public Health 2020, 17, 6366. [CrossRef] [PubMed]

29. Curcio, G.G.; Tempesta, D.; Scarlata, S.; Marzano, C.; Moroni, F.; Rossini, P.M.; Ferrara, M.; De Gennaro, L. Validity of the Italian Version of the Pittsburgh Sleep Quality Index (PSQI). Neurol. Sci. 2013, 34, 511-519. [CrossRef] [PubMed]

30. Buysse, D.J.; Reynolds, C.F.; Monk, T.H.; Berman, S.R.; Kupfer, D.J. Buysse DJ, Reynolds CF, Monk TH, Berman SR, Kupfer DJ. The Pittsburgh Sleep Quality Index: A new instrument for psychiatric practice and research. Psychiatry Res. 1989, 28, 193-213. [CrossRef]

31. Castronovo, V.; Galbiati, A.; Marelli, S.; Brombin, C.; Cugnata, F.; Giarolli, L.; Anelli, M.M.; Rinaldi, F.; Ferini-Strambi, L. Validation study of the Italian version of the Insomnia Severity Index (ISI). Neurol. Sci. 2016, 37, 1517-1524. [CrossRef]

32. Bastien, C.H.; Vallieres, A.; Morin, C.M. Validation of the Insomnia Severity Index as an outcome measure for insomnia research Sleep Med. 2001, 2, 297-307. [CrossRef]

33. Natale, V.; Esposito, M.J.; Martoni, M.; Fabbri, M. Validity of the reduced version of the Morningness-Eveningness Questionnaire. Sleep Biol. Rhythm. 2006, 4, 72-74. [CrossRef]

34. Ghisi, M.; Flebus, G.; Montano, A.; Sanavio, E.; Sica, C. Beck Depression Inventory, 2nd ed.; Adattamento Italiano: Manuale; Organizzazioni Speciali: Firenze, Italy, 2006.

35. Mondo, M.; Sechi, C.; Cabras, C. Psychometric evaluation of three versions of the Italian Perceived Stress Scale. Curr. Psychol. 2021, 40, 1884-1892. [CrossRef]

36. Spielberger, C.D.; Gorsuch, R.L.; Lushene, R.E. The State-Trait Anxiety Inventory (STAI) Test Manual for Form X; Consulting Psychologist Press: Palo Alto, Italy, 1970.

37. Sanavio, E.; Bertolotti, G.; Michelin, P.; Vidotto, G.; Zotti, A.M. CBA 2.0—Cognitive Behavioural Assessment 2.0—Scale Primarie: Manuale; Organizzazioni Speciali: Firenze, Italy, 1997.

38. Benjamini, Y.; Hochberg, Y. Controlling the False Discovery Rate: A Practical and Powerful Approach to Multiple Testing. J. R. Stat. Soc. Ser. B 1995, 57, 289-300. [CrossRef]

39. Salfi, F.; Lauriola, M.; Amicucci, G.; Corigliano, D.; Viselli, L.; Tempesta, D.; Ferrara, M. Gender-related time course of sleep disturbances and psychological symptoms during the COVID-19 lockdown: A longitudinal study on the Italian population. Neurobiol. Stress 2020, 13, 100259. [CrossRef] [PubMed] 
40. Altena, E.; Baglioni, C.; Espie, C.A.; Ellis, J.; Gavriloff, D.; Holzinger, B.; Schlarb, A.; Frase, L.; Jernelöv, S.; Riemann, D. Dealing with sleep problems during home confinement due to the COVID-19 outbreak: Practical recommendations from a task force of the European CBT-I Academy. J. Sleep Res. 2020, 29, e13052. [CrossRef] [PubMed]

41. Chong, Y.; Fryer, C.D.; Gu, Q. Prescription Sleep Aid use among Adults: United States, 2005-2010; NCHS Data Brief; National Centre for Health Statistic: Hyattsville, MD, USA, 2013.

42. Touitou, Y.; Touitou, D.; Reinberg, A. Disruption of adolescents' circadian clock: The vicious circle of media use, exposure to light at night, sleep loss and risk behaviors. J. Physiol. 2016, 110, 467-479. [CrossRef]

43. Randler, C.; Bilger, S.; Díaz-Morales, J.F. Associations among Sleep, Chronotype, Parental Monitoring, and Pubertal Development among German Adolescents. J. Psychol. 2009, 143, 509-520. [CrossRef]

44. Wittmann, M.; Dinich, J.; Merrow, M.; Roenneberg, T. Social Jetlag: Misalignment of Biological and Social Time. Chronobiol. Int. 2006, 23, 497-509. [CrossRef]

45. de Mendes, R.P.C.; Dunster, G.P.; de la Iglesia, H.O.; Menna-Barreto, L. Afternoon School Start Times Are Associated with a Lack of Both Social Jetlag and Sleep Deprivation in Adolescents. J. Biol. Rhythm. 2020, 35, 377-390. [CrossRef]

46. Wright, K.P.; Linton, S.K.; Withrow, D.; Casiraghi, L.; Lanza, S.M.; de la Iglesia, H.; Vetter, C.; Depner, C.M. Sleep in university students prior to and during COVID-19 Stay-at-Home orders. Curr. Biol. 2020, 30, R797-R798. [CrossRef]

47. MacLeod, S.; Musich, S.; Hawkins, K.; Alsgaard, K.; Wicker, E.R. The impact of resilience among older adults. Geriatr. Nurs. 2016, 37, 266-272. [CrossRef]

48. Scott, S.B.; Sliwinski, M.J.; Blanchard-Fields, F. Age differences in emotional responses to daily stress: The role of timing, severity, and global perceived stress. Psychol. Aging 2013, 28, 1076-1087. [CrossRef]

49. Uchino, B.N.; Berg, C.A.; Smith, T.W.; Pearce, G.; Skinner, M. Age-related differences in ambulatory blood pressure during daily stress: Evidence for greater blood pressure reactivity with age. Psychol. Aging 2006, 21, 231-239. [CrossRef]

50. Adan, A.; Archer, S.N.; Hidalgo, M.P.; Di Milia, L.; Natale, V.; Randler, C. Circadian Typology: A Comprehensive Review. Chronobiol. Int. 2012, 29, 1153-1175. [CrossRef]

51. Antúnez, J.M.; Navarro, J.F.; Adan, A. Circadian typology is related to resilience and optimism in healthy adults. Chronobiol. Int. 2015, 32, 524-530. [CrossRef]

52. Jeon, H.J.; Lee, S.-J. Chronobiology and Sleep on Resilience. Chronobiol. Med. 2019, 1, 149-151. [CrossRef]

53. Lee, S.-J.; Park, C.-S.; Kim, B.-J.; Lee, C.-S.; Cha, B.; Lee, Y.J.; Soh, M.; Park, J.A.; Young, P.S.; Song, E.H. Association between morningness and resilience in Korean college students. Chronobiol. Int. 2016, 33, 1391-1399. [CrossRef] [PubMed]

54. Romo-Nava, F.; Tafoya, S.; Gutiérrez, J.R.; Osorio, Y.; Carriedo, P.; Ocampo, B.; Bobadilla, R.I.; Heinze, G. The association between chronotype and perceived academic stress to depression in medical students. Chronobiol. Int. 2016, 33, 1359-1368. [CrossRef] [PubMed]

55. Hasler, B.P.; Insana, S.P.; James, J.A.; Germain, A. Evening-type military veterans report worse lifetime posttraumatic stress symptoms and greater brainstem activity across wakefulness and REM sleep. Biol. Psychol. 2013, 94, 255-262. [CrossRef] [PubMed]

56. Yun, J.-A.; Ahn, Y.-S.; Jeong, K.S.; Joo, E.-J.; Choi, K.-S. The Relationship between Chronotype and Sleep Quality in Korean Firefighters. Clin. Psychopharmacol. Neurosci. 2015, 13, 201-208. [CrossRef]

57. Salfi, F.; D'Atri, A.; Tempesta, D.; Ferrara, M. Sleeping under the waves: A longitudinal study across the contagion peaks of the COVID-19 pandemic in Italy. J. Sleep Res. 2021, 30, e13313. [CrossRef]

58. Elmer, T.; Mepham, K.; Stadtfeld, C. Students under lockdown: Comparisons of students' social networks and mental health before and during the COVID-19 crisis in Switzerland. PLoS ONE 2020, 15, e0236337. [CrossRef]

59. Sundarasen, S.; Chinna, K.; Kamaludin, K.; Nurunnabi, M.; Baloch, G.M.; Khoshaim, H.B.; Hossain, S.F.A.; Sukayt, A. Psychological Impact of COVID-19 and Lockdown among University Students in Malaysia: Implications and Policy Recommendations. Int. J. Environ. Res. Public Health 2020, 17, 6206. [CrossRef]

60. Lips, A. The Situation of Young People at Home During COVID-19 Pandemic. Child. Vulnerability J. 2021, 1-18. [CrossRef]

61. Salfi, F.; Amicucci, G.; Corigliano, D.; D'Atri, A.; Viselli, L.; Tempesta, D.; Ferrara, M. Changes of evening exposure to electronic devices during the COVID-19 lockdown affect the time course of sleep disturbances. Sleep 2021, 44, 1-9. [CrossRef] [PubMed]

62. Orchard, F.; Gregory, A.M.; Gradisar, M.; Reynolds, S. Self-reported sleep patterns and quality amongst adolescents: Crosssectional and prospective associations with anxiety and depression. J. Child Psychol. Psychiatry 2020, 61, 1126-1137. [CrossRef]

63. Smith, L.; Jacob, L.; Trott, M.; Yakkundi, A.; Butler, L.; Barnett, Y.; Armstrong, N.C.; McDermott, D.; Schuch, F.; Meyer, J.; et al. The association between screen time and mental health during COVID-19: A cross sectional study. Psychiatry Res. 2020, $292,113333$. [CrossRef] [PubMed]

64. Bruce, E.S.; Lunt, L.; McDonagh, J.E. Sleep in adolescents and young adults. Clin. Med. 2017, 17, 424-428. [CrossRef] [PubMed]

65. Alvaro, P.K.; Roberts, R.; Harris, J.K. A Systematic Review Assessing Bidirectionality between Sleep Disturbances, Anxiety, and Depression. Sleep 2013, 36, 1059-1068. [CrossRef]

66. Freeman, D.; Sheaves, B.; Goodwin, G.M.; Yu, L.-M.; Nickless, A.; Harrison, P.J.; Emsley, R.; Luik, A.I.; Foster, R.G.; Wadekar, V.; et al. The effects of improving sleep on mental health (OASIS): A randomised controlled trial with mediation analysis. Lancet Psychiatry 2017, 4, 749-758. [CrossRef] 